\author{
Asian Journal of \\ Medical and Biological Research \\ ISSN 2411-4472 \\ www.ebupress.com/journal/ajmbr
}

\title{
Article
}

\section{Molecular identification and antimicrobial resistance profiles of Campylobacter strains of poultry origin in India with special emphasis on fluoroquinolone resistance}

S. M. Lutful Kabir ${ }^{1,3^{*}}$, Masahiro Asakura ${ }^{1}$, Sachi Shiramaru ${ }^{1}$, Amit Pal $^{2}$, Atsushi Hinenoya ${ }^{1}$ and Shinji Yamasaki $^{1}$

${ }^{1}$ Graduate School of Life and Environmental Sciences, Osaka Prefecture University, Osaka, Japan

${ }^{2}$ Division of Bacteriology, National Institute of Cholera and Enteric Diseases, Kolkata, India

${ }^{3}$ Department of Microbiology and Hygiene, Faculty of Veterinary Science, Bangladesh Agricultural University, Mymensingh-2202, Bangladesh

*Corresponding author: Dr. S. M. Lutful Kabir, Department of Microbiology and Hygiene, Faculty of Veterinary Science, Bangladesh Agricultural University, Mymensingh-2202, Bangladesh. Tel.: +88-09167401-6/Ext. 2394; Fax: +88-091-61510; E-mail: 1kabir79@gmail.com

Received: 14 May 2015/Accepted: 08 June 2015/ Published: 30 June 2015

\begin{abstract}
The current study aimed to identify the selected number of Campylobacter strains of poultry origin in India that were isolated in the Laboratory of International Prevention of Epidemics, Graduate School of Life and Environmental Sciences, Osaka Prefecture University, Japan to the species level with the aid of $c d t A / B / C$ gene-based multiplex PCR assays as well as to investigate their antimicrobial resistance profiles. $C$. jejuni (4 strains) and C. coli (16 strains) were identified. The poultry isolates identified were subjected to susceptibility testing with the aid of disk diffusion method using 12 antimicrobial agents. Again, the resistant and intermediate isolates confirmed by the disk diffusion method were subjected to determination of minimum inhibitory concentration by agar dilution method. To elucidate the mechanism of quinolone resistance, a total number of 20 quinolone resistant strains were subjected to sequence determination and analysis of the gyrA gene in the quinolone-resistance determining region. The results of the disk diffusion method were consistent with the results of the agar dilution method with slight variation in case of ampicillin, levofloxacin, ofloxacin and fosfomycin. All $C$. jejuni and $C$. coli strains had the Thr 86 to Ile substitution in gyrA. Results of this study support the emergence of resistance of $C$. jejuni and $C$. coli strains of poultry origin in India to a variety of antimicrobials especially fluoroquinolones.
\end{abstract}

Keywords: identification; multiplex PCR; Campylobacter species; antimicrobial resistance

\section{Introduction}

Campylobacter, a gram negative, nonsporulating, motile bacterium, is commonly isolated as a pathogen associated with diarrhoea in many industrialized countries (Stanley and Jones, 2003). Chickens are frequently colonized by pathogenic Campylobacter species like C. jejuni and C. coli (Corry and Atabay, 2001). Campylobacter infections are primarily because of handling and consumption of raw or undercooked poultry and due to cross contamination (Stanley and Jones, 2003). Studies on isolation of Campylobacter from poultry meat have been carried out from the regions Tamilnadu and Calcutta using conventional method (Chowdhury $e t$ al., 1984; Varma et al., 2000). Although Campylobacter with resistance to antimicrobial agents has been reported worldwide (Looveren et al., 2001; Isenbarger et al., 2002), the situation seems to deteriorate more 
rapidly in developing countries, where there is widespread and uncontrolled use of antibiotics (Hart and Kariuki, 1998). Moreover, Campylobacter infections pose a serious public health problem for which many countries are monitoring their infection and antimicrobial resistance patterns. The current study was aimed to identify the selected number of Campylobacter strains of poultry origin in Calcutta, India that were isolated in the Laboratory of International Prevention of Epidemics, Graduate School of Life and Environmental Sciences, Osaka Prefecture University, Japan to the species level with the aid of $c d t A / B / C$ gene-based multiplex PCR assays as well as to investigate their antimicrobial resistance profiles.

\section{Materials and Methods}

\subsection{Bacterial strains and media}

A total of twenty Campylobacter strains isolated from poultry origin (cloacal swabs and raw poultry meat) in Calcutta, India were used in this study. E. coli ATCC 25922 was used as a quality control organism in antimicrobial susceptibility testing. All Campylobacter strains and E. coli ATCC 25922 were grown on blood base agar no. 2 (Oxoid, Basingstoke, UK) supplemented with 5\% (v/v) defibrinated horse blood (Nippon BioSupp. Center, Tokyo, Japan) under microaerobic conditions $\left(5 \% \mathrm{O}_{2}, 10 \% \mathrm{CO}_{2}\right.$ and $\left.85 \% \mathrm{~N}_{2}\right)$ at $37{ }^{\circ} \mathrm{C}$ for $48 \mathrm{hr}$.

\subsection{DNA preparation}

Template DNA was prepared by the boiling method as described by Hoshino et al. (1998). Briefly, a loopful of bacteria collected from agar plate was suspended in $1 \mathrm{ml}$ of TE buffer $[10 \mathrm{mM}$ Tris-HCl, $1 \mathrm{mM}$ EDTA (pH 8.0)] followed by boiling of the suspension for $10 \mathrm{~min}$, centrifugation at $12,800 \mathrm{~g}$ for $5 \mathrm{~min}$ and $2 \mu \mathrm{l}$ of supernatant was used as a PCR template.

\section{3. hipO gene PCR}

The hippuricase gene (hipO) was amplified by PCR using primers as described in Table 1 (Linton et al., 1997). The PCR reaction contained appropriate concentration of primer sets (Table 1), $0.2 \mathrm{mM}$ each of dNTP mixture (dATP, dCTP, dGTP, and dTTP), 1X Ex Taq DNA polymerase buffer, and 1.0 U of Ex Taq DNA polymerase in $40 \mu \mathrm{l}$ reaction volume. Amplification was performed on an Applied Biosystems GeneAmp PCR 9700 (Applied Biosystems). PCR products were analyzed by $1.5 \%$ agarose gel electrophoresis and bands were visualized with UV light after staining with ethidium bromide $(1 \mu \mathrm{g} / \mathrm{ml})$. Images were captured on a Bio-Rad Gel Doc system (Bio-Rad Laboratories, Hercules, CA, USA).

\subsection{Sequencing of the $16 S$ rRNA gene}

PCR primers for amplifying 16S rRNA gene are described in Table 1. Reaction mixture was as described above. PCR product was purified by a QIAquick PCR Purification Kit according to the manufacturer's instruction (QIAGEN GmbH, Hilden, Germany). The purified DNA was subjected to cycle sequencing reaction by using the BigDye Terminator Cycle Sequencing Kit (Applied Biosystems) with the primers used for 16S rRNA gene amplification and four additional primers, 16S520F (5'-GAGTTTGATCCTGGCTC-3), 16S1100F (5'-GCAACGAGCGCAACCC-3), 16S741R (5'-GTATCTAATCCTGTTTGC-3) and 16S1240R (5CCATTGTAGCACGTGT-3), which can specifically bind inner region of $16 \mathrm{~S}$ rRNA gene were also used. Nucleotide sequences were determined by using an ABI PRISM 3100-Avant Genetic Analyzer (Applied Biosystems). The sequences obtained were analyzed using the DNA Lasergene software package (DNASTAR, Madison, WI, USA). Homology searches were performed against all sequences in the GenBank database by using the BLAST search engine, available through the National Center for Biotechnology Information (NCBI) website (http://www.ncbi.nlm.nih.gov).

\subsection{Multiplex PCR}

The multiplex PCR assay for detection of $c d t A, c d t B$ and $c d t C$ genes of $C$. jejuni, $C$. coli and $C$. fetus was performed by gene specific primers (Asakura et al., 2008) are summarized in Table 1. All reactions contained appropriate concentrations of three primer sets, $0.2 \mathrm{mM}$ each of dNTP mixture, 1X Ex Taq DNA polymerase buffer, and 1.0 U of Ex Taq DNA polymerase in a $40-\mu \mathrm{L}$ reaction volume. PCR products were analyzed by $2 \%$ agarose gel electrophoresis and visualization of bands and capturing of image were done as described above. 


\subsection{Antimicrobial agents and susceptibility testing}

All Campylobacter strains were tested against ampicillin $(10 \mu \mathrm{g})$, tetracycline $(30 \mu \mathrm{g})$, azithromycin $(15 \mu \mathrm{g})$, erythromycin $(15 \mu \mathrm{g})$, chloramphenicol $(30 \mu \mathrm{g})$, gentamicin $(10 \mu \mathrm{g})$, nalidixic acid $(30 \mu \mathrm{g})$, ciprofloxacin $(5$ $\mu \mathrm{g})$, levofloxacin $(5 \mu \mathrm{g})$, ofloxacin $(5 \mu \mathrm{g})$, fosfomycin $(50 \mu \mathrm{g})$ and sulphamethoxazole-trimethoprim $(1.25 \mu \mathrm{g})$ by disk diffusion method as described by Luangtongkum et al. (2007) with some modifications. Again, all intermediately resistant and resistant Campylobacter strains confirmed by disk diffusion method except sulphamethoxazole-trimethoprim resistant strains were subjected to the determination of minimum inhibitory concentration (MIC) by agar dilution method as described by Luangtongkum et al. (2007) with some modifications. The antimicrobial resistance break points (Minimum inhibitory concentration: MIC) used were those established by national antimicrobial resistance monitoring system (NARMS) in accordance with Clinical and Laboratory Standards Institute (CLSI) guidelines: ampicillin, $\geq 32 \mu \mathrm{g} \mathrm{ml}^{-1}$; tetracycline, $\geq 16 \mu \mathrm{g} \mathrm{ml}^{-1}$; azithromycin, $\geq 8 \mu \mathrm{g} \mathrm{ml}^{-1}$; erythromycin, $\geq 8 \mu \mathrm{g} \mathrm{ml}^{-1}$; chloramphenicol, $\geq 32 \mu \mathrm{g} \mathrm{ml}^{-1}$; gentamicin, $\geq 16 \mu \mathrm{g} \mathrm{ml}^{-1}$; nalidixic acid, $\geq 32 \mu \mathrm{g} \mathrm{ml}^{-1}$; ciprofloxacin, $\geq 4 \mu \mathrm{g} \mathrm{ml}^{-1}$; levofloxacin, $\geq 8 \mu \mathrm{g} \mathrm{ml}^{-1}$; ofloxacin, $\geq 8 \mu \mathrm{g} \mathrm{ml}{ }^{-1}$. Resistance to fosfomycin was considered when the MIC was $\geq 128 \mu \mathrm{g} / \mathrm{ml}$ (Andrews et al., 1983). All susceptibility data were confirmed on at least two separate experiments.

\subsection{PCR amplification of the gyrA gene}

PCR amplification of the gyrA gene was performed by PCR primers and conditions as described by Zirnstein $e t$ al. (1999 \& 2000).

\subsection{Sequence determination}

PCR products of the gyrA genes were purified by a QIAquick PCR Purification Kit according to the manufacturer's instruction (QIAGEN GmbH, Hilden, Germany). The purified DNA was subjected to cycle sequencing reaction by using the BigDye Terminator Cycle Sequencing Kit (Applied Biosystems) and primers used for the gyrA genes amplification. The reactions were conducted in a GeneAmp 9700 thermal cycler (Applied Biosystems) in accordance with the manufacturer's instruction. Nucleotide sequences were determined by using an ABI PRISM 3100-Avant Genetic Analyzer (Applied Biosystems). Homology searches were performed against all sequences in the GenBank database by using the BLAST search engine, available through the National Center for Biotechnology Information (NCBI) website (http://www.ncbi.nlm.nih.gov). Nucleotide and amino acid sequence alignments were subsequently generated by MegAlign and ClustalW programs in the lasergene software package (DNASTAR, Madison, WI, USA). DNA Sequences of $C$. jejuni UA580 (GenBank accession number L04566) and C. coli RM 2228 (GenBank accession number NZ_AAFL01000007) were used for making comparison with the gyrA genes sequences obtained in this study.

\section{Results and Discussion}

The summary of the species identification of Campylobacter strains of poultry origin in India by molecular methods are presented in Tables 2 and 3. Among the 20 Campylobacter strains isolated from poultry origin in India, 4 were identified as $C$. jejuni and the rest 16 were identified as $C$. coli with the aid of hipO gene based PCR, 16S rRNA gene sequencing and $c d t A / B / C$ gene based multiplex PCR assays. Detection of $C$. jejuni and $C$. coli by $c d t B$ gene-based multiplex PCR are shown in Figures 1 and 2. $C d t$ gene-based multiplex PCR assays appeared to be best for the accurate identification of Campylobacter strains. Routine detection of Campylobacter species in most clinical laboratories is based on culture method using selective media and following phenotypic identification (Maher et al., 2003). However, phenotypic identification can be challenging because of the fastidious growth requirements, the asaccharolytic nature and possession of few distinguishing biochemical characteristics of campylobacters (Goossens \& Butzler, 1992). The only biochemical test for discriminating between $C$. jejuni and $C$. coli is based on hippurate hydrolysis activity, which is time consuming, cumbersome and sometimes difficult to interpret the result when the enzymatic activity is impaired under the methodological conditions (Totten et al., 1987; Rautelin et al., 1999). Thus, genetic methods can be a possible alternative. Singh et al. (2009) isolated $C$. jejuni and $C$. coli in chicken meat and carcass swabs collected from local poultry farms and retail shops of Bareilly, Uttar Pradesh, India. The results of antimicrobial susceptibility of Campylobacter strains of poultry origin in India by disk diffusion method are summarized in Table 4. In case of C. jejuni, $100 \%$ isolates were sensitive to ampicillin, azithromycin, erythromycin, chloramphenicol and gentamicin. However, $100 \%$ isolates were resistant to tetracycline, nalidixic acid, ciprofloxacin, levofloxacin, ofloxacin and sulphamethoxazole-trimethoprim. 
On the other hand, in case of $C$. coli, $100 \%$ isolates were sensitive to azithromycin, erythromycin, chloramphenicol, gentamicin and fosfomycin. However, 100\% isolates were resistant to nalidixic acid, ciprofloxacin and sulphamethoxazole-trimethoprim. Susceptibility tests for campylobacter species are not standardized (there is no recommendation by the CLSI), so there are variabilities in the susceptibility reported (Vandenberg et al., 2006). However, we used disk diffusion method for the susceptibility testing of $C$. jejuni and $C$. coli strains used in this study followed by determination of MIC of the intermediately resistant and resistant strains by agar dilution method (Luangtongkum et al., 2007). Susceptibility testing of Campylobacter species is important to facilitate appropriate treatment where indicated and also for surveillance of emergence of drug resistance. The present findings were closely related with the findings of Jain et al., 2005.

The distribution of MICs for $C$. jejuni and $C$. coli isolates from poultry origin in India are presented in Table 5. In case of $C$. jejuni strains $(\mathrm{n}=4), 100 \%$ isolates were resistant to tetracycline (MIC, $128 \mu \mathrm{g} / \mathrm{ml})$, nalidixic acid (MIC, $128 \mu \mathrm{g} / \mathrm{ml}$ ), ciprofloxacin (MIC, $64 \mu \mathrm{g} / \mathrm{ml}$ ), sulfamethoxazole-trimethoprim, levofloxacin (MIC, 16 $\mu \mathrm{g} / \mathrm{ml}$ ) and ofloxacin (MIC, $32 \mu \mathrm{g} / \mathrm{ml}$ ) whereas $25 \%$ isolates were resistant to fosfomycin (MIC, 32-64 $\mu \mathrm{g} / \mathrm{ml}$ ) and all $C$. jejuni strains had the Thr 86 to Ile and Asn 203 to Ser substitution in GyrA (Table 6). On the other hand, in case of $C$. coli strains ( $\mathrm{n}=16$ ), $100 \%$ isolates were resistant to nalidixic acid (MIC, 32-128 $\mu \mathrm{g} / \mathrm{ml}$ ), ciprofloxacin (MIC, 4-128 $\mu \mathrm{g} / \mathrm{ml}$ ) and sulfamethoxazole-trimethoprim whereas $93.75 \%$ isolates were resistant to levofloxacin (MIC, 2-16 $\mu \mathrm{g} / \mathrm{ml}$ ) and ofloxacin (MIC, 4-32 $\mu \mathrm{g} / \mathrm{ml}$ ) followed by $62.5 \%$ were resistant to ampicillin (MIC, $16-32 \mu \mathrm{g} / \mathrm{ml}$ ) and $43.75 \%$ were resistant to tetracycline (MIC, $128 \mu \mathrm{g} / \mathrm{ml}$ ) and one C. coli strains had the Thr 86 to Ile and Met 181 to Arg substitution in GyrA and the rest 15 strains had only Thr 86 to Ile substitution in GyrA (Table 6). For Campylobacter strains, high-level resistance to fluoroquinolones is mostly mediated by mutations within the QRDR of the gyrA gene, of which replacement of C256 with T leading to a Thr-86-Ile substitution in GyrA is predominant (Ge et al., 2003; Vacher et al., 2003; Payot et al., 2006; Bakeli et al., 2008).

Table 1. Primers used for the $c d t$ genes based multiplex PCR, hipO gene PCR and 16S rRNA gene amplification.

\begin{tabular}{|c|c|c|c|}
\hline Primer & Sequence (5'-3') & Target & Reference \\
\hline$\overline{\mathrm{Cj}-\mathrm{CdtAU} 2}$ & AGGACTTGAACCTACTTTTC & $C j c d t A$ & Asakura et al., 2008 \\
\hline Cj-CdtAR2 & AGGTGGAGTAGTTAAAAACC & & \\
\hline Cc-CdtAU1 & ATTGCCAAGGCTAAAATCTC & Cc cdtA & \\
\hline Cc-CdtAR 1 & GATAAAGTCTCCAAAACTGC & & \\
\hline Cf-CdtAU1 & AACGACAAATGTAAGCACTC & $C f c d t A$ & \\
\hline Cf-CdtAR1 & TATTTATGCAAGTCGTGCGA & & \\
\hline Cj-CdtBU5 & ATCTTTTAACCTTGCTTTTGC & $C j c d t B$ & Asakura et al., 2008 \\
\hline Cj-CdtBR6 & GCAAGCATTAAAATCGCAGC & & \\
\hline Cc-CdtBU5 & TTTAATGTATTATTTGCCGC & $C c c d t B$ & \\
\hline Cc-CdtBR5 & TCATTGCCTATGCGTATG & & \\
\hline Cf-CdtBU6 & GGCTTTGCAAAAACCAGAAG & $C f c d t B$ & \\
\hline Cf-CdtBR3 & CAAGAGTTCCTCTTAAACTC & & \\
\hline Cj-CdtCU1 & TTTAGCCTTTGCAACTCCTA & $C j c d t C$ & Asakura et al., 2008 \\
\hline $\mathrm{Cj}-\mathrm{CdtCR} 2$ & AAGGGGTAGCAGCTGTTAA & & \\
\hline $\mathrm{Cc}-\mathrm{CdtCU} 1$ & TAGGGATATGCACGCAAAAG & $C c c d t C$ & \\
\hline Cc-CdtCR 1 & GCTTAATACAGTTACGATAG & & \\
\hline Cf-CdtCU2 & AAGCATAAGTTTTGCAAACG & $C f c d t C$ & \\
\hline Cf-CdtCR2 & GTTTGGATTTTCAAATGTTCC & & \\
\hline HIP400F & GAAGAGGGTTTGGGTGGTG & hippuricase & Linton et al., 1997 \\
\hline HIP1134R & AGCTAGCTTCGCATAATAACTTG & gene & \\
\hline $16 \mathrm{~S} 9 \mathrm{~F}$ & GAGTTTGATCCTGGCTC & 16S rRNA & Samosornsuk et al., 2007 \\
\hline $16 \mathrm{~S} 1540 \mathrm{R}$ & AAGGAGGTGATCCAGCC & gene & \\
\hline
\end{tabular}


Table 2. The summary of the species identification of Campylobacter strains of poultry origin in India.

\begin{tabular}{|c|c|c|c|c|}
\hline \multirow[t]{2}{*}{ Screening methods } & \multirow{2}{*}{$\begin{array}{l}\text { Total no. of } \\
\text { strains tested }\end{array}$} & \multicolumn{2}{|c|}{ No. of PCR positive strains } & \multirow{2}{*}{$\begin{array}{c}\text { No. of PCR } \\
\text { negative strains }\end{array}$} \\
\hline & & C. jejuni & C. coli & \\
\hline hịO gene PCR & 20 & 4 & - & $16^{A}$ \\
\hline$c d t A$ gene based M-PCR & 20 & 4 & 16 & - \\
\hline cdtB gene based M-PCR & 20 & 4 & 16 & - \\
\hline$c d t C$ gene based M-PCR & 20 & 4 & 16 & - \\
\hline
\end{tabular}

${ }^{A}$ These 16 strains were subjected to $16 \mathrm{~S}$ rRNA gene sequencing and sequence data were trimmed and adjusted to $1,335 \mathrm{bp}$ to perform homology searches and all were identified as $\mathrm{C}$. jejuni / C. coli.

Table 3. 16S rRNA gene sequencing for the identification of Campylobacter strains of poultry origin in India.

\begin{tabular}{|c|c|c|c|}
\hline Sample No. & Amplicon size (bp) & Query length (bp) & 16S rRNA gene sequence \\
\hline $1-1 a$ & $\mathbf{1 , 5 3 0}$ & 1,335 & C. jejuni ${ }^{1} /$ C. coli $^{2}$ \\
\hline $1-2 a$ & $\mathbf{1 , 5 3 0}$ & 1,335 & C. jejuni ${ }^{1} /$ C. coli $^{2}$ \\
\hline $1-3 b$ & 1,530 & 1,335 & C. jejuni $^{1} /$ C. coli $^{2}$ \\
\hline $1-4 a$ & 1,530 & 1,335 & C. jejuni ${ }^{1} /$ C. coli $^{2}$ \\
\hline $7-1 a$ & 1,530 & 1,335 & C. jejuni $^{1} /$ C. coli $^{2}$ \\
\hline $7-2 b$ & $\mathbf{1 , 5 3 0}$ & 1,335 & C. jejuni ${ }^{1} /$ C. coli $^{2}$ \\
\hline $8-1 a$ & 1,530 & 1,335 & C. jejuni ${ }^{1} /$ C. coli $^{2}$ \\
\hline 8-2d & 1,530 & 1,335 & C. jejuni ${ }^{3} /$ C. coli $^{4}$ \\
\hline $9-1 b$ & 1,530 & 1,335 & C. jejuni ${ }^{1} /$ C. coli $^{2}$ \\
\hline $9-2 a$ & $\mathbf{1 , 5 3 0}$ & 1,335 & C. jejuni ${ }^{1} /$ C. coli $^{2}$ \\
\hline $9-3 c$ & 1,530 & 1,335 & C. jejuni ${ }^{1} /$ C. coli $^{2}$ \\
\hline $9-4 a$ & 1,530 & 1,335 & C. jejuni ${ }^{3} /$ C. coli $^{4}$ \\
\hline $10-1 d$ & 1,530 & 1,335 & C. jejuni $^{3} /$ C. coli $^{4}$ \\
\hline $10-2 d$ & 1,530 & 1,335 & C. jejuni $^{5} /$ C. coli $^{6}$ \\
\hline $10-3 a$ & $\mathbf{1 , 5 3 0}$ & 1,335 & C. jejuni ${ }^{3} /$ C. coli $^{4}$ \\
\hline $10-4 c$ & $\mathbf{1 , 5 3 0}$ & 1,335 & C. jejuni ${ }^{3} /$ C. coli $^{4}$ \\
\hline
\end{tabular}

\footnotetext{
${ }^{1}$ Accession No. GQ167679, C. jejuni strain INN-73-83 094400, Identities = 1335/1335 (100\%)

${ }^{2}$ Accession No. GQ167673, $C$. coli strain X10, Identities = 1335/1335 (100\%)

${ }^{3}$ Accession No. GQ479817, $C$. jejuni strain SWUN0717, Identities = 1332/1335 (99\%)

${ }^{4}$ Accession No. GQ167673, C. coli strain X10, Identities = 1332/1335 (99\%)

${ }^{5}$ Accession No. GQ479819, $C$. jejuni strain SWUN1202, Identities = 1334/1335 (99\%)

${ }^{6}$ Accession No. GQ167673, $C$. coli strain X10, Identities = 1334/1335 (99\%)
}

Table 4. Antimicrobial susceptibility of Campylobacter strains of poultry origin in India.

\begin{tabular}{|c|c|c|c|c|c|c|c|c|c|c|c|c|}
\hline \multirow{2}{*}{$\begin{array}{l}\text { Campylobacter } \\
\text { spp. }\end{array}$} & \multicolumn{12}{|l|}{ No. $(\%)$} \\
\hline & $\mathrm{ABPC}$ & $\mathrm{TC}$ & $\mathrm{AZMM}$ & EM & $\mathrm{CP}$ & $\mathrm{GM}$ & NA & CPFX & LVFX & OFLX & FOM & ST \\
\hline \multicolumn{13}{|l|}{ C. jejini ( $\mathrm{r}=4)$} \\
\hline S & $4(100)$ & - & $4(100)$ & $4(100)$ & $4(100)$ & $4(100)$ & - & - & - & - & - & - \\
\hline I & - & - & - & - & - & - & - & - & - & - & $3(75)$ & - \\
\hline$\underline{\mathrm{R}}$ & - & $4(100)$ & - & - & - & - & $4(100)$ & $4(100)$ & $4(100)$ & $4(100)$ & $1(25)$ & $4(100)$ \\
\hline \multicolumn{13}{|l|}{ C. coli $(\mathrm{n}=16)$} \\
\hline$S$ & $6(37.5)$ & $9(56.25)$ & $16(100)$ & $16(100)$ & $16(100)$ & $16(100)$ & - & - & $1(625)$ & $1(625)$ & $16(100)$ & - \\
\hline I & - & - & - & - & - & - & - & - & - & - & - & - \\
\hline$\underline{\mathrm{R}}$ & $10(62.5)$ & $7(43.75)$ & - & - & - & - & $16(100)$ & $16(100)$ & $15(93.75)$ & $15(93.75)$ & - & $16(100)$ \\
\hline
\end{tabular}

ABPC: ampicillin; TC: tetracycline; AZM: azithromycin; EM: erythomycin; CP: chloramphenicol; GM: gentamicin; HA: nalidixic acid; CPFX: cipofloxacin; LVFX: levofloxacin; OFLX: ofloxacin; FOM: fosfomycin; ST: sulphamethoxazole-trimethopim; S: Susceptible; I: Intermediate; R: Resistant 
Tab le 5. Distrib ution of MICs for C. jejuni and C. coli isolates from poultry origin in India.

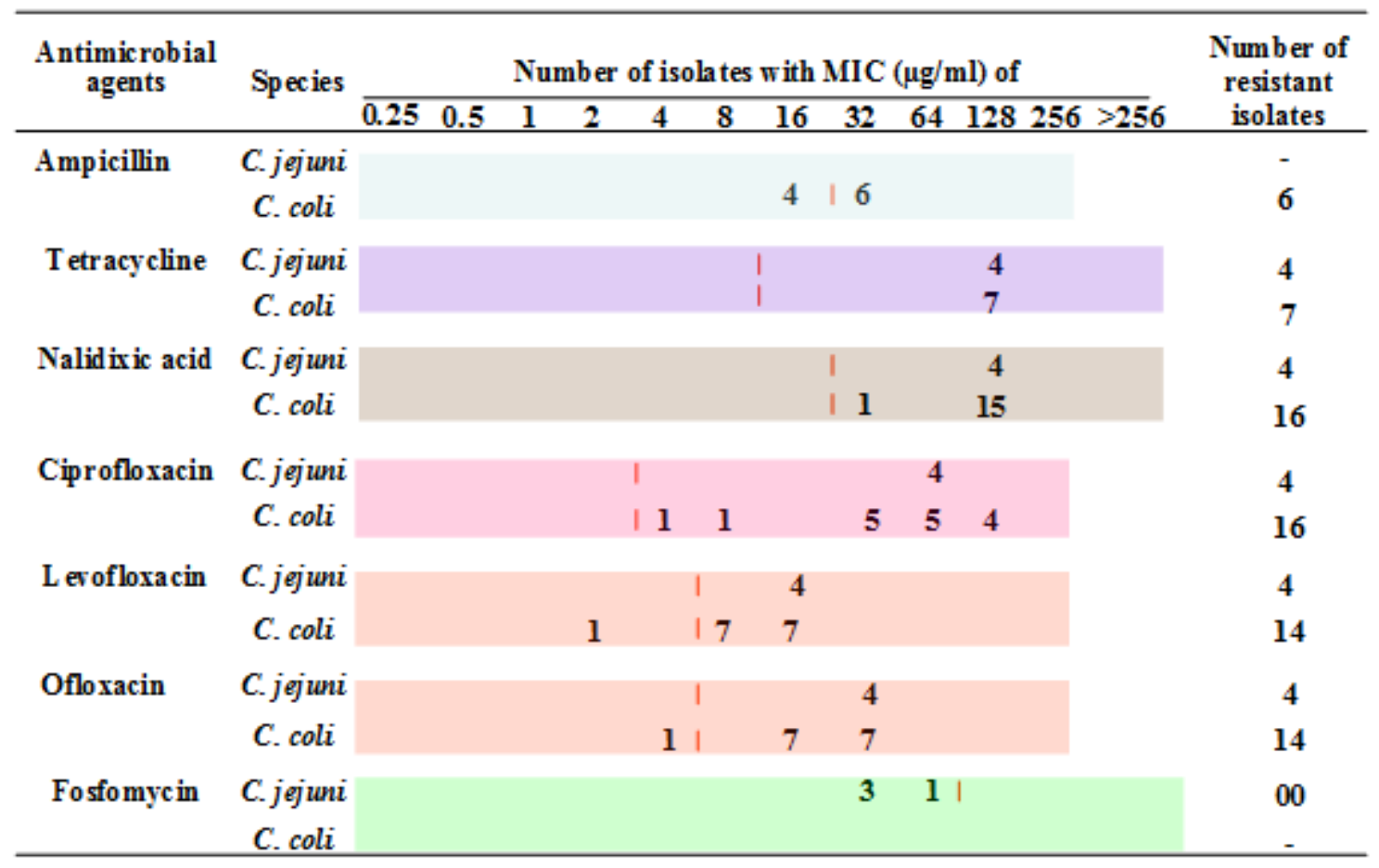

Vertical lines ( ) indicate b reakp oints for resistance.

Highlighted regions are the dilution ranges used in the agar dilution.

Table 6. Point mutations observed in gyrA sequences of C. Jejuni and C. coll strains of poultry origin in India.

\begin{tabular}{|c|c|c|c|c|c|}
\hline \multirow[t]{2}{*}{ Species } & \multicolumn{3}{|c|}{$g y r A$ mutation (s) } & \multirow{2}{*}{$\begin{array}{c}\text { MIC of ciprofloxacin } \\
(\mu g / \mathrm{ml})\end{array}$} & \multirow{2}{*}{$\begin{array}{l}\text { No. of } \\
\text { strains }\end{array}$} \\
\hline & Thr86Ile & Met181Arg & Asn203Ser & & \\
\hline C. jejuni & + & - & + & 64 & 4 \\
\hline C. coli & $\begin{array}{l}+ \\
+\end{array}$ & $\begin{array}{l}+ \\
-\end{array}$ & - & $\begin{array}{c}128 \\
4-128\end{array}$ & $\begin{array}{c}1 \\
15\end{array}$ \\
\hline
\end{tabular}

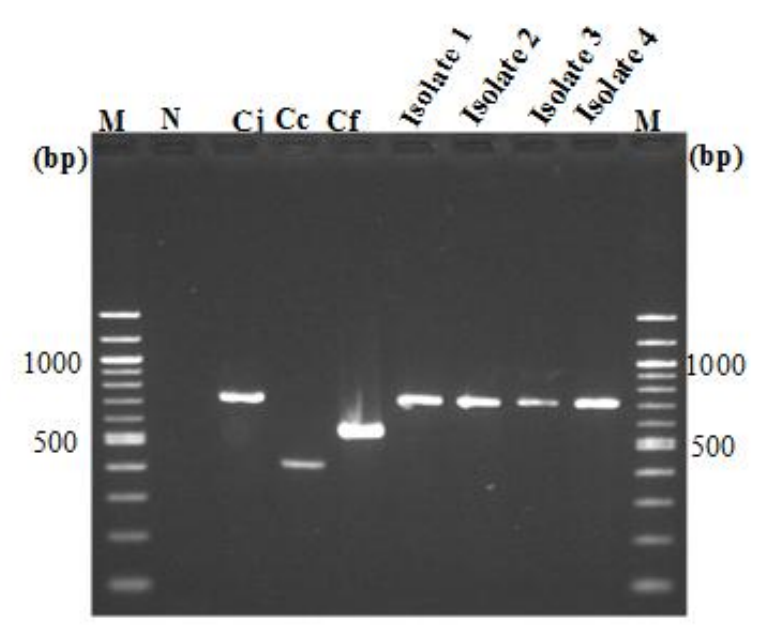

$2 \%$ SeaKem ME Agarose Gel (Cambrex Bio Science Rockland, Inc. Rockland, ME USA)

M: 100 bp ladder (New England Biolabs Inc., Beverly, MA, USA)

$\mathrm{N}$ : Negative control (E. coli $\mathrm{C} 600)$

Figure l. Detection of Campylobacter jejuni by $c d t B$ gene-based multiplex PCR. 


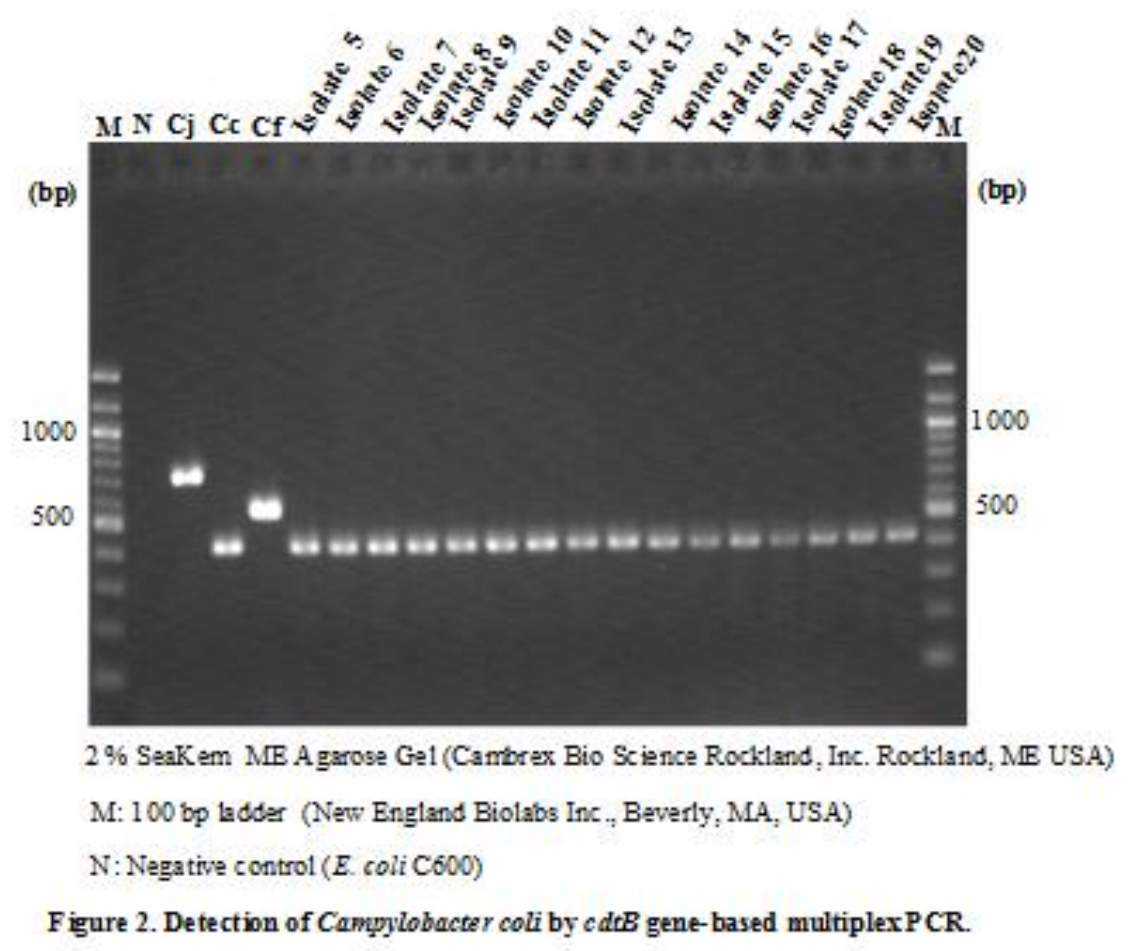

\section{Conclusions}

Results of this study support the emergence of resistance of $C$. jejuni and $C$. coli strains of poultry origin in India to a variety of antimicrobials especially fluoroquinolones. Erythromycin should still be the drug of choice in treatment since all C. jejuni/coli strains were sensitive to the drug in this study.

\section{Acknowledgements}

An earlier version of this paper was presented at the Eighth International Poultry Show and Seminar, Dhaka, Bangladesh during 28 February-02 March 2013. We thank Professor Dr. M. Mansurul Amin, Department of Microbiology and Hygiene, Bangladesh Agricultural University, Mymensingh-2202, Bangladesh for his critical corrections and suggestions on the manuscript.

\section{Conflict of interest}

None to declare.

\section{References}

Andrews JM, F Baquero, JM Beltran, E Canton, F Crokaert, M Gobernado, R Gomez-Lus, E Loza, M Navarro, T Olay, A Rodriguez, MV Vicente, R Wise and E Yourassowsky, 1983. International collaborative study on standardization of bacterial sensitivity to fosfomycin. J. Antimicrob. Chemother.,12:357-361.

Asakura M, W Samosornsuk, A Hinenoya, N Misawa, K Nishimura, A Matsuhisa and S Yamasaki, 2008. Development of a cytolethal distending toxin $(c d t)$ gene-based species-specific multiplex PCR assay for the detection and identification of Campylobacter jejuni, Campylobacter coli and Campylobacter fetus. FEMS Immunol. Med. Microbiol., 52:260-266.

Bakeli G, K Sato, W Kumita, R Saito, E Ono, T Chida and N Okamura, 2008. Antimicrobial susceptibility and mechanism of quinolone resistance in Campylobacter jejuni strains isolated from diarrheal patients in a hospital in Tokyo. J. Infect. Chemother., 14:342-348.

Chowdhury S, GB Nair and SC Pal, 1984. Occurrence of Campylobacter jejuni in country chicken in Calcutta. Indian J. Med. Res., 79: 171-173.

Corry JEL and HI Atabay, 2001. Poultry as a source of Campylobacter and related organisms. J. Appl. Microbiol., 90: 965-1145. 
Jain DS, S Sinha, KN Prasad and CM Pandey, 2005. Campylobacter species and drug resistance in a north Indian rural community. Trans. R. Soc. Trop. Med. Hyg., 99: 207-214.

Ge B, DG White, PF McDermott, W Girard, S Zhao, S Hubert and J Meng, 2003. Antimicrobial-resistant Campylobacter species from retail raw meats. Appl. Environ. Microbiol., 69:3005-3007.

Goossens H and JP Butzler, 1992. Isolation and identification of Campylobacter species, p. 93-109. In Nachamkin I, Blaser MJ, Tompkins LS (ed.), Campylobacter jejuni: current status and future trends. American Society for Microbiology, Washington, DC.

Hart CA and S Kariuki, 1998. Antimicrobial resistance in developing countries. Br. Med. J., 317: 647-650.

Hoshino K, S Yamasaki, AK Mukhopadhyay, S Chakraborty, A Basu, SK Bhattacharya, GB Nair, T Shimada and Y Takeda, 1998. Development of evaluation of a multiplex PCR assay for rapid detection of toxigenic Vibrio cholerae O1 and O139. FEMS Immunol. Med. Microbiol., 20:201-207.

Isenbarger DW, CW Hoge, A Srijan, C Pitarangsi, N Vithayasai and L Bodhidatta, 2002. Comparative antibiotic resistance of diarrheal pathogens from Vietnam and Thailand, 1996-1999. Emerg. Infect. Dis., 8: 175-180.

Linton D, AJ Lawson, RJ Owen and J Stanley, 1997. PCR detection, identification to species level, and fingerprinting of Campylobacter jejuni and C. coli direct from diarrheic samples. J. Clin. Microbiol., 35:25682572.

Looveren MV, G Daube, L De Zutter, JM Dumont, C Lammens and M Wijdooghe, 2001. Antimicrobial susceptibilities of Campylobacter strains isolated from food animals in Belgium. Antimicrob. Agents Chemother., 48: 235-240.

Luangtongkum T, AB Morishita El-Tayeb, AJ Ison and Q Zhang, 2007. Comparison of antimicrobial susceptibility testing of Campylobacter spp. by the agar dilution and the agar disk diffusion methods. J. Clin. Microbiol., 45:590-594.

Maher M, C Finnegan, E Collins, B Ward, C Carroll and M Cormican, 2003. Evaluation of culture methods and a DNA probe-based PCR assay for detection of Campylobacter species in clinical specimens. J. Clin. Microbiol., 41:2980-2986.

Payot S, JM Bolla, D Corcoran, S Fanning, F Megraud and Q Zhang, 2006. Mechanisms of fluoroquinolone and macrolide resistance in Campylobacter spp. Microb. Infect., 8:1967-1971.

Singh R, PP Singh, RS Rathore, K Dhama and SVS Malik, 2009. Prevalence of Campylobacter jejuni and Campylobacter coli in chicken meat and carcasses collected from local poultry farms and retail shops of Bareilly, Uttar Pradesh, India. Indian J. Comp. Microbiol. Immunol. Infect. Dis. 30: 35-38.

Rautelin H, J Jusufovic and ML Hanninen, 1999. Identification of hippurate-negative thermophilic campylobacters. Diagn. Microbiol. Infect. Dis. 35:9-12.

Silley P, 2003. Campylobacter and fluoroquionolones: a bias data set. Environ. Microbiol., 5: 219-230.

Totten PA, CM Patton, FC Tenover, TJ Barrett, WE Stamm, AG Steigerwalt, JY Lin, K K Holmes and DJ Brenner, 1987. Prevalence and characterization of hippurate-negative Campylobacter jejuni in King County, Washington. J. Clin. Microbiol. 25:1747-1752.

Vacher S, A Menard, E Bernard and F Megraud, 2003. PCR-restriction fragment length polymorphism analysis for detection of point mutations associated with macrolide resistance in Campylobacter spp. Antimicrob. Agents Chemother., 47:1125-1128.

Vandenberg O, K Houf, N Douat, L Vlaes, P Retore, J Butzler and A. Dediste, 2006. Antimicrobial susceptibility of clinical isolates of non-jejuni/coli campylobacters and arcobacters from Belgium. J. Antimicrob. Chemother., 57:908-913.

Varma SK, N Jagadeesh, HK Mukhopadhyay and N Dorairajan, 2000. Incidence of Campylobacter jejuni in poultry and their carcasses. J. Food Sci. Tech., 37: 639-641.

Zirnstein G, L Helsel, Y Li, B Swaminathan and J Besser, 2000. Characterization of gyrA mutations associated with fluoroquinolone resistance in Campylobacter coli by DNA sequence analysis and MAMA PCR. FEMS Microbiol. Lett. 190:1-7.

Zirnstein G, Y Li, B Swaminathan and F Angulo, 1999. Ciprofloxacin resistance in Campylobacter jejuni isolates: detection of $g y r A$ resistance mutations by mismatch amplification mutation assay PCR and DNA sequence analysis. J. Clin. Microbiol., 37:3276-3280. 